\title{
Selection of Construction Bidders Using the Analytical Hierarchy Process and Friedman Theory
}

\begin{abstract}
Alaa Salman *
Department of Civil and Construction Engineering, College of Engineering, Imam Abdulrahman Bin Faisal University, Dammam, Saudi Arabia

Selecting a suitable bidder to execute a construction project is not an easy task, especially for the short bidder list. The consequences of the selection might affect the project performance in terms of cost, money, and quality. The current research in this work deals with the selection of a contractor, who bids on a specific project. The historical data of contractors are a key of the selection based on three approaches: the quick selection approach (QSA), generic selection approach (GSA), and comprehensive selection approach (CSA). The QSA relies on the scoring system according to delay factors. The QSA is the weighted average of the delay factors using the analytical hierarchy process (AHP), the CSA is based on the integrated QSA and the bidding strategy using Friedman's theory. The current three approaches can be utilized by public and private owners, who intend to select a general contractor to execute new construction projects. A hypothetical case study is implemented to demonstrate the developed models. Several experts in the field of construction management have confirmed the findings. The third strategy (CSA) is found to be the most appropriate for selecting construction bidders.
\end{abstract}

OPEN ACCESS

Edited by:

Fahim Ullah,

University of Southern Queensland, Australia

Reviewed by:

Hafiz Zahoor

National University of Sciences and Technology, Pakistan Samir El-Omari, University of Wisconsin-Platteville, United States

*Correspondence: Alaa Salman akalobaidi@iau.edu.sa

Specialty section: This article was submitted to Construction Management, a section of the journa Frontiers in Built Environment

Received: 14 November 2021 Accepted: 15 December 2021

Published: 28 January 2022

Citation:

Salman A (2022) Selection of Construction Bidders Using the Analytical Hierarchy Process and Friedman Theory.

Front. Built Environ. 7:815022. doi: 10.3389/fbuil.2021.815022

Keywords: Construction Projects, General Contractors, AHP, Bidding Strategy, Friedman Theory

\section{INTRODUCTION}

The construction project market is one of the largest industrial markets in the world. Billions of dollars have been pumped into this industry in Saudi Arabia to fulfill Saudi vision 2030. The value of the construction projects that began construction in Saudi Arabia is about USD 819 billion between 2019 and 2024 (Modor Intelligence, 2019). Currently, numerous construction projects are operated by hundreds of national and international companies. For competitive bidding contracts, selecting a general contracting company is a key factor to achieve the vision. Owners of public and private projects require a systematic method to select a specific contractor among tens of contractors. The long list is usually updated to be a shortlist, which contains five (maybe three to ten) bidders in general. In most cases, one bidder is selected to carry out the new project. The crucial question is "how an owner selects? And, what is the rationale behind the selection?" This question has many answers; however, most of these answers are related to the current and previous performances of the bidders. Historical data include previous performances and activities of the previous projects. Accordingly, utilizing such data to perform a systematic method is logical to help owners in the selection process. But the level of interaction of data usage has changed from simple to very complicated. For instance, the scoring of some factors (such as delay factors) is a quick method of the selection, while using very complicated operation research methods with the utilizing of the historical data require experts in this field if the process is not automated. The current research deals with 
different historical data of bidders with respect to three levels of complexity: simple, medium, and advanced. The main objective of the current research is to build a new system, to help publicand private-owned companies select a suitable bidder as follows:

i. Identify and rank the most important delay factors caused by contractors,

ii. Quick selection approach (QSA): based on the scoring of bidder delay factors,

iii. Generic selection approach (GSA): with respect to an average weight of the bidder delay factors, and

iv. Comprehensive selection approach (CSA): according to GAS and Friedman theory.

Researchers have developed several systems according to several criteria. Profile (2016) listed most of the historical bidding strategy models such as the subjective criteria, probability of winning based on the risk pattern, individual bidders through the variables of the bidder size, contract value and project type, bid/no bid decision, and number and identities of bidders competing for a particular contract. Multicriteria and fuzzy preference relation (FPR) models are proposed to help contractors bid/not bid, and the optimum markup of bidding (Cheng et al., 2011; Araujo et al., 2015) designed a systematic decision-making framework to select a contractor according to the stages of the project. Moreover, several delay factors are listed and finalized with the most cited delay factors which are price, health and safety, past project performance, duration, experience in similar jobs, and quality. A game theory is utilized to help bidders with respect to hidden costs (Kembłowski et al., 2017). A probability-based method is presented for estimating the optimal bid price (Jaskowski et al., 2019). ELECTRE TRI is employed to classify the contractors into three categories: good, moderate, and bad. De Araujo et al. (2017) and Yang (2018) mentioned that linear programming and decision tree are utilized to select whether the contractor bid or did not bid to the construction project. Liang et al. (2016) concluded that owners can select suitable contractors based on their performances using individual and collaborative information. A conceptual model is developed for the overall project delay with respect to owners, consultants, contractors, project, and external factors. Using SPSS to analyze the experts' responses, delay factors are ranked accordingly (Van et al., 2016). Most of the previous systems have dealt with delay factors, which are the key of the bidder selection; therefore, it is necessary to include previous studies to support the current research. A fish-bone model is developed to illustrate the cause and effect of delay problems in public projects. Bekr (2017) and Al-Adwani et al. (2018) addressed the risk factors that affect the Middle East construction industry. Using reliability analysis, the factors are checked to be standardized using Cronbach's alpha (Ca). Gomarn and Pongpeng (2018). performed a confirmatory factor analysis (CFA) to analyze delay factors caused by the contractors and suppliers of Thailand's oil and gas projects; they determined the relation is very high between them. Zidane and Andersen (2018) identified several delay factors with their frequencies and solutions in major Norwegian projects. Ruqaishi and Bashir (2015) developed a conceptual framework to identify delay categories in the oil and gas construction industries. The categories are construction management issues, design issues, client performance, acts of God, and secondary issues. Fashina et al. (2021) ranked several delay factors affecting the construction project in using the relative importance index (RII) in Hargeisa (Somalia). The delay factors are divided into owners, clients, material, equipment, consultants, labor, and external factors. Yap et al. (2021) conducted a comprehensive literature to collect delay factors globally. A total of 52 common causes of delay are identified from the literature review using meta-analysis. From a bidder's side, winning a construction project bid is subjected to several factors such as the number of bidders, the historical performances of the bidders, the nature of the project, the cost of the project, and expected risks. The Friedman theory (Friedman, 1956) is the first theory that addressed the bidding strategy to win a bid. A bidder can estimate the optimum markup of winning a bid based on the previous bids of the competitors using statistical models. Marzouk and Moselhi (2003) mentioned that other theories such as those by Anthony and Gates (2007), Carr (1982) used statistical methods for winning a bid as well. Rzepecki and Jaśkowski (2021) proposed a mathematical model to minimize the maximum loss with respect to the Friedman theory. Rao (2013) described that the Friedman theory is the formal start of auction theory research. Christodoulou (2010) improved the Friedman theory by applying artificial neural networks and an entropy metric. Jaskowski et al. (2019) concluded that the Friedman theory depends on several assumptions, which might be not real such as it follows a specific probability distribution, which is not correct when the market is changed. As a conclusion, most of the previous research studies have dealt with the Friedman theory from the bidder's side. The current research utilized the Friedman theory from the owner's side, which has not been considered before.

\section{MATERIALS AND METHODS}

Figure 1 depicts the methodology of the bidder selection. The required input to form the database of an owner is the contractor delay factors, bidder historical data, and previous projects' data. When several bidders bid for a new project, the owner needs to store all necessary data to be utilized for the selection process in the new project. These data require a specific database, which needs to be arranged and updated accordingly. The owner can select one of the three approaches: quick selection, generic selection, and comprehensive selection after the filtering process as follows:

\section{Filtering Process}

Figure 2 identifies the selection of construction bidder filters. It includes the following: 


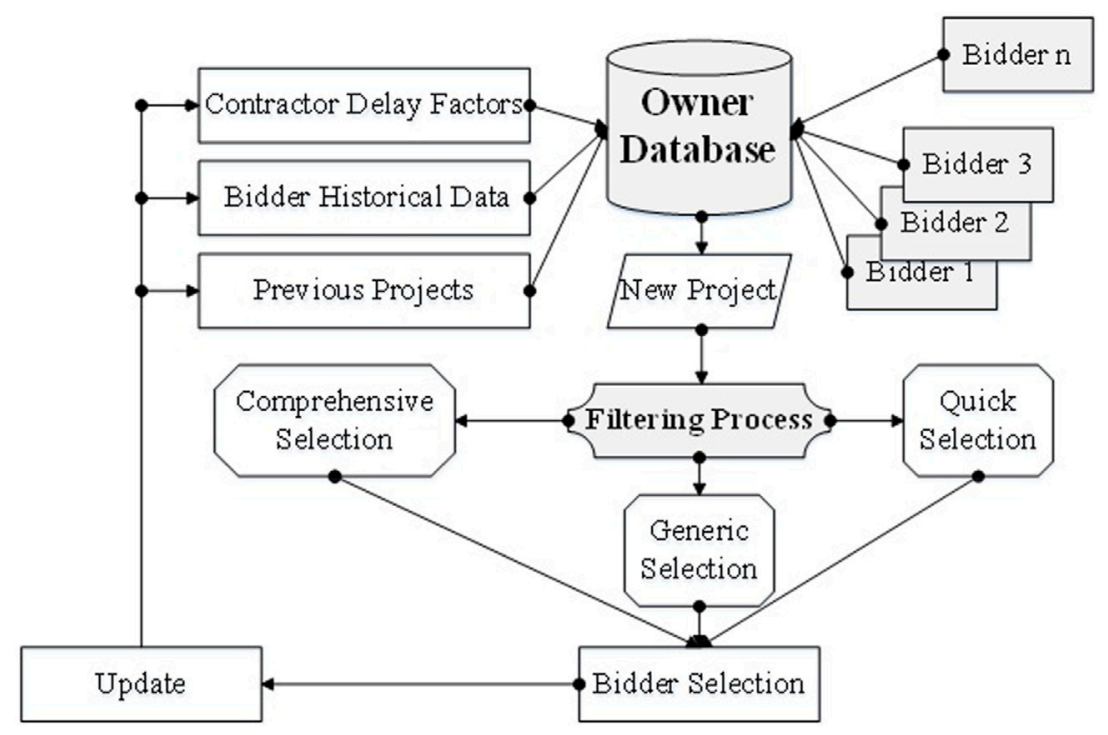

FIGURE 1 | Methodology Selection of the Construction Bidder.

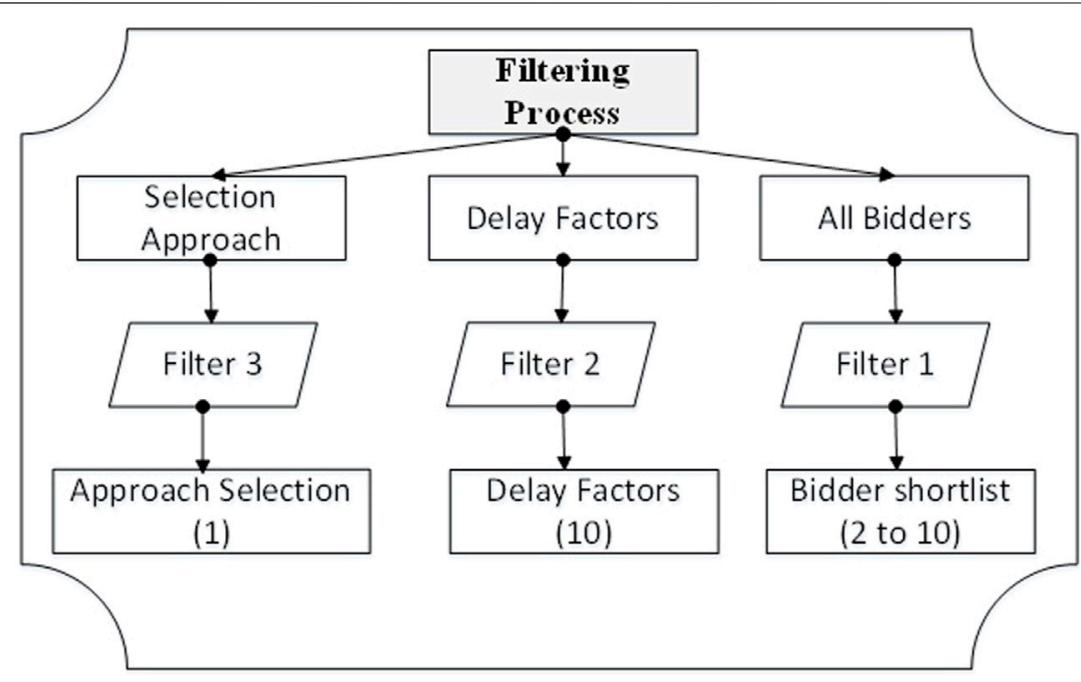

FIGURE 2 | Filtering Process.

\section{Filter 1: Shortlist the Bidders}

Shortlisting the number of bidders is very important to select only competent bidders. Mathematically, the shortlist of the bidders is subjected to Eq. 1. Qualified bidders are filtered based on several factors $(q)$ such as reputation, liability, legality, financial capacity, availability, and conflict of interest. These factors are represented as a binary value, either zero or one. The qualified bidders, who get one $\left(Q_{i}\right.$ $=1$ ), are qualified, and they are part of the shortlist. Otherwise $\left(\mathrm{Q}_{\mathrm{i}}=0\right)$, the bidders are out of the bidding if one (or more than one) of these factors is not applied to the bidders. This assumption is very important to shorten the list of bidders when the number of bidders is not limited.

$$
Q_{i}=\Pi_{p=1}^{\mathrm{P}} q_{p}
$$

where

$\mathrm{Q}_{\mathrm{i}}$ : Qualification of the bidder $\mathrm{i}^{\text {th }}$.

$q_{p}$ : qualification factor

$p$ : qualification factor number out of $\mathrm{P}$.

\section{Filter 2: Shortlist the Delay Factors}

Ten specific factors are implemented by default. However, the current version is limited to a fixed number of the delay factors. In fact, it is not logical to consider numerous factors, which leads to complicated processes and wasting time and effort. For the 
TABLE 1 | Causes of delay

\begin{tabular}{|c|c|c|c|c|c|c|c|c|c|}
\hline No & Delay factor (DF) & 1 & 2 & 3 & 4 & 5 & Total reviewers & RII & Selected \\
\hline 1 & Lack of manpower & 1 & 3 & 3 & 5 & 18 & 30 & 0.840 & Yes \\
\hline 2 & Contractor financial issues & 0 & 3 & 6 & 10 & 11 & 30 & 0.793 & \\
\hline 3 & Lack of labor skills & 1 & 2 & 11 & 6 & 10 & 30 & 0.747 & \\
\hline 4 & Contractor planning and scheduling deficiency & 0 & 5 & 6 & 11 & 8 & 30 & 0.747 & \\
\hline 5 & Low productivity & 0 & 3 & 9 & 12 & 6 & 30 & 0.740 & \\
\hline 6 & Defective material and mistakes during construction & 0 & 6 & 9 & 5 & 10 & 30 & 0.727 & \\
\hline 7 & Poor procurement system management & 1 & 5 & 8 & 14 & 2 & 30 & 0.673 & \\
\hline 8 & Poor communication and coordination with others & 1 & 7 & 9 & 7 & 6 & 30 & 0.667 & \\
\hline 9 & Delays in site mobilization & 3 & 4 & 9 & 11 & 3 & 30 & 0.647 & \\
\hline 10 & Lack of safety rules and regulations & 3 & 5 & 12 & 4 & 6 & 30 & 0.633 & \\
\hline 11 & Late payment to suppliers & 0 & 9 & 11 & 7 & 3 & 30 & 0.627 & No \\
\hline 12 & neglect of owner requirement & 4 & 7 & 6 & 7 & 6 & 30 & 0.627 & \\
\hline 13 & Delay in preparation of shop drawings & 4 & 4 & 13 & 4 & 5 & 30 & 0.613 & \\
\hline 14 & Inadequate contractor experience & 5 & 6 & 7 & 11 & 1 & 30 & 0.580 & \\
\hline 15 & Improper material storage which causes its deterioration & 6 & 6 & 9 & 4 & 5 & 30 & 0.573 & \\
\hline 16 & Poor site management and supervision & 2 & 12 & 8 & 6 & 2 & 30 & 0.560 & \\
\hline 17 & Poor management decision-making & 8 & 5 & 6 & 9 & 2 & 30 & 0.547 & \\
\hline 18 & Incomplete or improper design & 7 & 9 & 6 & 6 & 2 & 30 & 0.513 & \\
\hline 19 & Poor estimation practice & 7 & 8 & 9 & 3 & 3 & 30 & 0.513 & \\
\hline 20 & Sub-contractors work delay & 4 & 14 & 10 & 1 & 1 & 30 & 0.473 & \\
\hline 21 & Resource shortage & 10 & 13 & 4 & 2 & 1 & 30 & 0.407 & \\
\hline 22 & Change of sub-contractor & 14 & 10 & 3 & 0 & 3 & 30 & 0.387 & \\
\hline
\end{tabular}

current research, 22 factors have been selected according to the literature review and after several direct meetings with experts in this field. Later, a questionnaire was used to rank these factors, and the top ten using the relative importance index (RII) based on 30 experts were selected, as shown in Table 1. The ten factors are adopted in this research as default delay factors; however, a user can modify these factors with respect to ten only.

\section{Filter 3: Approach Selection}

In this filter, three approaches are available: the quick selection approach (QSA), generic selection approach (GSA), and comprehensive selection approach (CSA). The QSA is suitable for quick and limited data. It requires the score of the ten delay factors (1-9). The GSA is appropriate if an owner decides to consider the scoring and the importance weights of the delay factors. The CSA is used when the bidding history of the bidders is required in addition to the scoring and importance weights of the delay factors.

\section{Quick Selection Approach}

In this approach, a bidder is selected regarding the delay factors only. This process is used extensively by owners around the world. An owner evaluates the bidders according to a scale of " 1 " to " 9 " (or a different scale) using several delay factors. When " 1 " is assigned to a bidder for a specific delay factor, it represents no delay, while "9" depicts extreme delay. By adding the scores of all delay factors, the total score (TBS1) shows the final evaluation of the bidder. The bidder can be selected when he/she obtains the minimum total score, as shown in Eq. 2. However, several owners use this scale in reverse; the selected bidder is based on the maximum instead of the minimum total score, which is not suitable when the delay factors are the base of the comparison among the bidders. The qualification of the bidder $(Q=1)$ is added to the equation to connect the pre-selection with the selection. The bidders are on the shortlist in this stage because the value $\mathrm{Q}$ is one.

$$
T B S 1_{\mathrm{i}}=\mathrm{Q}_{\mathrm{i}} \times\left[\Sigma_{\mathrm{j}=1}^{\mathrm{m}} D F_{J}\right] .
$$

The bidder selected is subjected to the following:

$$
\text { Min. }[T B S 1]_{i=1}^{n} \text {, }
$$

where

$T B S 1_{i}$ : Total bidder score of the $\mathrm{i}^{\text {th }}$ contractor using the first approach (QSA)

j: Delay factor number

$\mathrm{m}$ : Number of delay factors

DF: Delay factor

$\mathrm{n}$ : Number of bidders

\section{Generic Selection Approach}

With this approach, a new dimension is added to the QSA to adjust the delay factor scores. The importance weight of each delay factor is considered, and therefore, a delay factor has a specific score (1-9) and a generic weight (\%). Both values, the specific and generic, are multiplied to obtain the adjusted scores of delay factors. A bidder with a minimum total score (TBS2), Eq. 3, may be selected accordingly. The analytical hierarchy process (AHP) (Hussain et al., 2015) is utilized to determine the importance weights of the delay factors.

$$
\operatorname{TBS}_{i}=Q_{i} \times\left[\sum_{j=1}^{m}(D F \times W)_{j}\right] .
$$

The bidder selected is subjected to

$$
\operatorname{Min} .\left[T B S 2_{i}\right]_{i=1}^{n} \text {, }
$$

where 
TBS2 $2_{i}$ : Total bidder score of the $\mathrm{i}^{\mathrm{th}}$ contractor using the second approach (GSA)

W: Delay factor weight

\section{Comprehensive Selection Approach}

This approach requires more information to be carried out using historical data of the bidders. A new dimension is added to the GSA, as shown below in Eq. 4. The " $k$ " value has a proportional relationship with the total bidder score (TBS3). The high value of " $k$ " minimizes the TBS3 and vice versa. In the current research, " $k$ " is equal to or more than zero; when $\mathrm{k}$ is equal to zero, the total bidding score of the $\mathrm{i}^{\text {th }}$ bidder using comprehensive (CSA) and generic (GSA) selection approaches have the same results. Otherwise, the two approaches have different values.

$$
T B S 3_{i}=Q_{i} \times\left[1+k_{i}\right] \times\left[\left\{\sum_{j=1}^{\mathrm{m}}(D F \times W)_{j}\right\}\right] .
$$

The bidder selected is subjected to

where

$$
\text { Min. }\left[\text { TBS3 } 3_{i}\right]_{i=1}^{n} \text {, }
$$

$k$ : A random value

$T B S 3_{i}$ : Total bidder score of the $\mathrm{i}^{\text {th }}$ contractor using the third approach (CSA).

After studying several previous biddings coupled with extensive research, we have realized the following:

a) There is a strong relationship between the bidders' markups and their chances of winning the new bid,

b) A bidder with a high markup gives a negative impression to the owner's decision,

c) The difference between the optimum and the new markup of the bidder is another indication by the owner towards the bidder's performance risk. A slight difference means that the new project is well known by the bidder, and therefore, his/her expected risk is low. On the other hand, high risk is expected by the bidder when the difference is high.

If " $k$ " is assumed to represent the difference between the current markup of the bidder and his/her optimum winning markup. When " $k$ " is high, which means that the bidder risk is high, it leads to a high value of the total bidder score (TBS3) of the $\mathrm{i}^{\text {th }}$ bidder, which minimizes the bidder's chance to win the bid, simply his/her current bid is not logical. From the history of a bidder and previous projects, the optimum markup to win the new project can be estimated using several methods such as Friedman (Yuliana et al., 2016), Gate (Anthony and Gates, 2007), and Carr (Ballesteros-Pérez et al., 2014). In addition, the absolute sign is added to measure the difference only between the current and optimum wining markup, as shown in Equation 5.

$$
\mathrm{k}_{\mathrm{i}}=\mid\left\{(\text { Markup })_{\text {current }}-(\text { Markup })_{\text {winning }}\right\}_{\mathrm{i}} \mid \text {. }
$$

Therefore, " $k$ " is redefined as a bidding strategy reference of the $i^{\text {th }}$ bidder and $k_{i} \geq 0$. Hence, the total score of a bidder using the third approach (CSA) is performed using Eq. 6.

$$
\begin{aligned}
& \text { TBS3 }_{i}=Q_{i} \times\left[1+\mid\left\{\left(\text { Markup }_{\text {current }}-\left(\text { Markup }_{\text {winning }}\right\}_{i} \mid\right]\right.\right. \\
& \times\left\{\sum_{j=1}^{m}(D F \times W)_{j}\right\}
\end{aligned}
$$

where

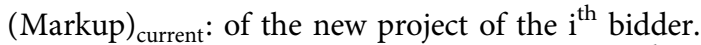

(Markup) $)_{\text {winning }}$ : of winning the project by the $\mathrm{i}^{\text {th }}$ bidder.

\section{RESULTS}

\section{Model Application}

A hypothetical example is implemented to depict the developed model. The XYZ company would like to select a contractor to execute a 100 -milliondollar construction project. More than 20 bidders are applied to win the bid. The owner filters the bidders using Eq. 1 to select five bidders only, as shown in Table 2. The shortlist of the bidders with their bids is shown in Table 3. The markup of each bidder is shown in the last column. The owner is not obligated to select the minimum bid due to the sensitivity of the project. The company has historical data of the five bidders. Data include the following:

a) Performances (delay scores) of the previous projects, as shown in Table 4. The ten delay factors are utilized according to Table 1.

b) The previous bidding, as depicted in Table 5 .

\section{Quick Selection Approach}

Using Tables 2, 4; Eq. 2; Figure 3, TBS1 of Danny is the lowest value, 39 points, and therefore, he is suitable to be selected to execute the new project. More TBS1 values mean more risk due to previous performances of the bidders. The bidder "Basim" has the highest TBS1 value, 50 points; accordingly, he is the last one to be selected in the shortlist. The bidder 'Essam' is the second bidder to be selected after Danny. His TBS1 is 40; the difference is not big, so he may be selected if Danny cannot fulfill the other administrative requirements before starting the project. It should be noted that the other administrative requirements are not within the objectives of the current research.

\section{Generic Selection Approach}

The importance weights of the delay factors are considered for the selection in this approach. The analytical hierarchy process (AHP) is used to determine the importance weights of the delay factors. Using the pair-wise comparison of the delay factors by 12 experts, the results of the importance weights are shown in Table 6. The consistency matrix is checked accordingly, and the result is considered accepted. The consistency ratio (CR\%) is less than (10\%), and therefore, there is no need to re-evaluate the pair-wise matrix again. By merging the TBS1 results from Table 2 and the importance weights, which are obtained from Table 6, Equation 3 is performed to determine TBS2 of the bidders, as shown in Table 7 and Figure 4. The result of this approach shows that the bidder 
TABLE 2 | Filter one- Shortlisted the bidders.

\begin{tabular}{|c|c|c|c|c|c|c|c|}
\hline $\begin{array}{l}\text { Bidder's name } \\
\text { (1) }\end{array}$ & $\begin{array}{l}\text { Availability } \\
\text { (2) }\end{array}$ & $\begin{array}{l}\text { Legality } \\
\text { (3) }\end{array}$ & $\begin{array}{l}\text { Liability } \\
\text { (4) }\end{array}$ & $\begin{array}{l}\text { Financial capacity } \\
\text { (5) }\end{array}$ & $\begin{array}{l}\text { Conflict of interest } \\
\text { (6) }\end{array}$ & $\begin{array}{l}\text { Qualification Factors } \\
(7)=(2) .(3) .(4) .(5) .(6)\end{array}$ & $\begin{array}{c}\text { Shortlist } \\
\text { (8) }\end{array}$ \\
\hline Ahmad & 1 & 1 & 1 & 1 & 1 & 1 & Yes \\
\hline Daniel & 0 & 1 & 1 & 0 & 1 & 0 & No \\
\hline Farrah & 1 & 1 & 0 & 0 & 1 & 0 & No \\
\hline Basim & 1 & 1 & 1 & 1 & 1 & 1 & Yes \\
\hline Gabriel & 0 & 1 & 1 & 1 & 1 & 0 & No \\
\hline Ben & 0 & 0 & 1 & 1 & 0 & 0 & No \\
\hline Georgie & 1 & 1 & 1 & 1 & 0 & 0 & No \\
\hline Cameron & 1 & 1 & 1 & 1 & 1 & 1 & Yes \\
\hline Bob & 1 & 1 & 0 & 1 & 1 & 0 & No \\
\hline David & 0 & 1 & 1 & 0 & 0 & 0 & No \\
\hline Amin & 1 & 1 & 1 & 0 & 0 & 0 & No \\
\hline Harry & 1 & 0 & 1 & 1 & 1 & 0 & No \\
\hline Danny & 1 & 1 & 1 & 1 & 1 & 1 & Yes \\
\hline Bella & 0 & 1 & 1 & 1 & 1 & 0 & No \\
\hline Harrison & 0 & 1 & 1 & 0 & 0 & 0 & No \\
\hline Essam & 1 & 1 & 1 & 1 & 1 & 1 & Yes \\
\hline Katie & 1 & 1 & 1 & 1 & 0 & 0 & No \\
\hline Lucas & 1 & 1 & 1 & 1 & 0 & 0 & No \\
\hline Michael & 1 & 1 & 0 & 1 & 1 & 0 & No \\
\hline
\end{tabular}

TABLE 3 | Current bidding and markup.

Bidder name

Bid (million \$) “B”

\begin{tabular}{lr}
\hline Ahmad & 110 \\
Basim & 115 \\
Cameron & 108 \\
Danny & 112 \\
Essam & 120
\end{tabular}

Project estimated cost (million \$) "C"

Markup $(\%)=(B / C)-1$

100
100
100
100
100

10

15

8

12

20

TABLE 4 | Delay factor scores.

Delay factor

Lack of manpower
Contractor financial issues
Lack of labor skills
Contractor planning and scheduling deficiency
Low productivity
Defective material and mistakes during construction
Poor procurement system management
Poor communication and coordination with others
Delays in site mobilization
Lack of safety rules and regulations
Total

\section{Lack of manpower}

contractor financial issues

Low productivity

struction

Poor communication and coordination with others

Lack of safety rules and regulations

Total
Bidder Delay Score (1: Minimum -9: Maximum)

\begin{tabular}{lccccc}
\hline & Ahmad & Basim & Cameron & Danny & Essam \\
DF1 & 6 & 4 & 3 & 2 & 6 \\
DF2 & 4 & 3 & 2 & 8 & 6 \\
DF3 & 3 & 4 & 4 & 3 & 2 \\
DF4 & 5 & 5 & 5 & 4 & 3 \\
DF5 & 7 & 6 & 3 & 3 & 7 \\
DF6 & 8 & 7 & 7 & 9 & 4 \\
DF7 & 2 & 4 & 5 & 3 & 3 \\
DF8 & 1 & 3 & 3 & 1 & 2 \\
DF9 & 3 & 6 & 4 & 4 & 3 \\
DF10 & 4 & 5 & 44 & 39 & 40 \\
\end{tabular}

TABLE 5 | Bidder historical data.

\begin{tabular}{|c|c|c|c|c|c|c|}
\hline \multirow[t]{2}{*}{ Project\# } & \multirow[t]{2}{*}{ Project cost (\$) } & \multicolumn{5}{|c|}{ Bidding (\$) } \\
\hline & & Ahmad & Basim & Cameron & Danny & Essam \\
\hline 1 & $10,800,000$ & $12,852,000$ & $12,096,000$ & $13,176,000$ & $13,608,000$ & $14,040,000$ \\
\hline 2 & $32,900,000$ & $38,493,000$ & $39,809,000$ & $37,835,000$ & $40,138,000$ & $38,822,000$ \\
\hline 3 & $38,000,000$ & $44,840,000$ & $45,600,000$ & $46,740,000$ & $47,120,000$ & $45,980,000$ \\
\hline 4 & $43,000,000$ & $46,200,000$ & $47,100,000$ & $45,300,000$ & $44,900,000$ & $45,100,000$ \\
\hline 5 & $56,000,000$ & $58,300,000$ & $57,900,000$ & $58,100,000$ & $58,200,000$ & $57,700,000$ \\
\hline
\end{tabular}




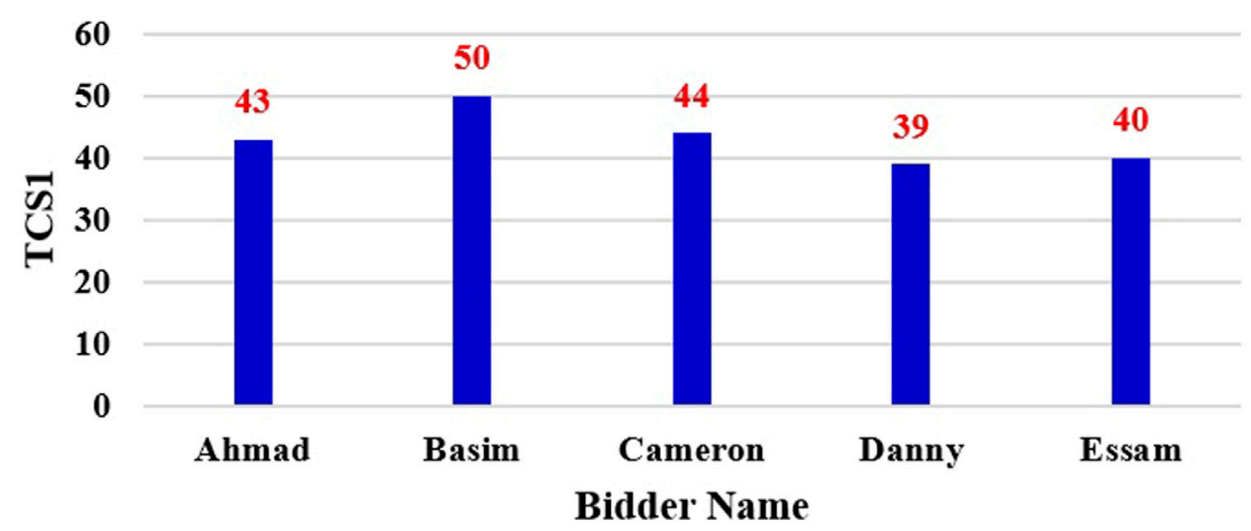

FIGURE 3 | Bidder ranking using the QSA

TABLE 6 | Importance weights of the delay factors using AHP.

\begin{tabular}{|c|c|c|c|c|c|c|c|c|c|c|}
\hline $\begin{array}{l}\text { Delay } \\
\text { Factor } 1\end{array}$ & $\begin{array}{c}\text { Delay } \\
\text { Factor } 2\end{array}$ & $\begin{array}{c}\text { Delay } \\
\text { Factor } 3\end{array}$ & $\begin{array}{c}\text { Delay } \\
\text { Factor } 4\end{array}$ & $\begin{array}{c}\text { Delay } \\
\text { Factor } 5\end{array}$ & $\begin{array}{c}\text { Delay } \\
\text { Factor } 6\end{array}$ & $\begin{array}{c}\text { Delay } \\
\text { Factor } 7\end{array}$ & $\begin{array}{c}\text { Delay } \\
\text { Factor } 8\end{array}$ & $\begin{array}{c}\text { Delay } \\
\text { Factor } 9\end{array}$ & $\begin{array}{c}\text { Delay } \\
\text { Factor } 10\end{array}$ & $\begin{array}{c}\text { Importance } \\
\text { Weight }\end{array}$ \\
\hline 1.000 & 0.500 & 0.333 & 0.400 & 0.250 & 0.333 & 0.400 & 0.333 & 0.250 & 1.111 & 0.040 \\
\hline 2.000 & 1.000 & 0.667 & 0.500 & 0.400 & 0.333 & 0.500 & 1.000 & 0.556 & 0.500 & 0.059 \\
\hline 3.000 & 1.500 & 1.000 & 1.111 & 1.250 & 0.714 & 0.625 & 1.429 & 1.250 & 0.909 & 0.105 \\
\hline 2.500 & 2.000 & 0.900 & 1.000 & 0.667 & 0.667 & 0.500 & 1.429 & 1.250 & 1.111 & 0.100 \\
\hline 4.000 & 2.500 & 0.800 & 1.500 & 1.000 & 1.000 & 1.111 & 0.833 & 0.500 & 0.333 & 0.098 \\
\hline 3.000 & 3.000 & 1.400 & 1.500 & 1.000 & 1.000 & 0.500 & 0.333 & 0.500 & 0.556 & 0.095 \\
\hline 2.500 & 2.000 & 1.600 & 2.000 & 0.900 & 2.000 & 1.000 & 0.333 & 0.400 & 0.333 & 0.101 \\
\hline 3.000 & 1.000 & 0.700 & 0.700 & 1.200 & 3.000 & 3.000 & 1.000 & 1.250 & 1.111 & 0.127 \\
\hline 4.000 & 1.800 & 0.800 & 0.800 & 2.000 & 2.000 & 2.500 & 0.800 & 1.000 & 4.000 & 0.154 \\
\hline 0.900 & 2.000 & 1.100 & 0.900 & 3.000 & 1.800 & 3.000 & 0.900 & 0.250 & 1.000 & 0.121 \\
\hline
\end{tabular}

TABLE 7 | TBS2 results.

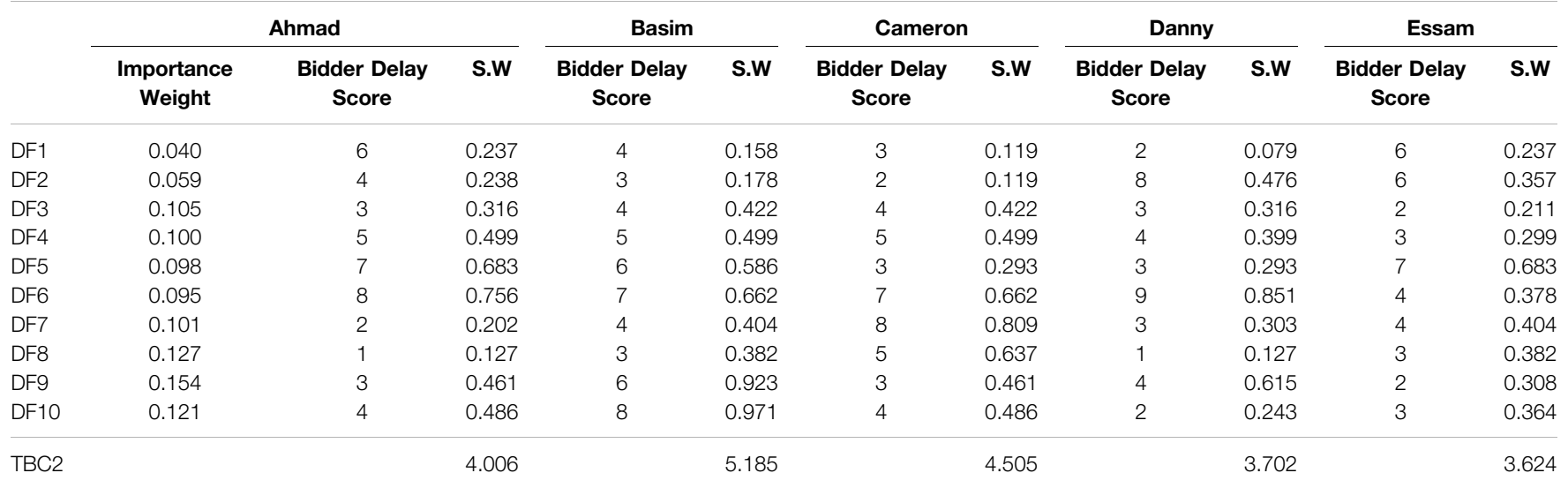

"Essam" has the lowest value of TBS2, which is 3.624. This result is different than the QSA results; however, by considering the importance weights of the delay factors, the results of GSA are more reliable. The bidder "Basim" is still at the bottom of the shortlist of the five bidders.

\section{Comprehensive Selection Approach}

To obtain the " $k$ " value, two indicators are required: the current markup and the winning markup. The current markup is estimated in Table 3, based on the bid cost ratio of the current project. The current markup is equal to the $\mathrm{B} / \mathrm{C}$ 
TABLE 8 | Optimum markup of winning the new project by the bidder "Ahmad".

Project

Bidding cost ratio $(\mathrm{B} / \mathrm{C})$

\begin{tabular}{|c|c|c|c|c|c|c|c|c|c|}
\hline & \multicolumn{2}{|c|}{ Basim } & \multicolumn{2}{|c|}{ Cameron } & \multicolumn{2}{|c|}{ Danny } & \multicolumn{2}{|c|}{ Essam } & \\
\hline 1 & \multicolumn{2}{|c|}{1.120} & \multicolumn{2}{|c|}{1.220} & \multicolumn{2}{|c|}{1.260} & \multicolumn{2}{|c|}{1.300} & \\
\hline 2 & \multicolumn{2}{|c|}{1.210} & \multicolumn{2}{|c|}{1.150} & \multicolumn{2}{|c|}{1.220} & \multicolumn{2}{|c|}{1.180} & \\
\hline 3 & \multicolumn{2}{|c|}{1.200} & \multicolumn{2}{|c|}{1.230} & \multicolumn{2}{|c|}{1.240} & \multicolumn{2}{|c|}{1.210} & Ahmad is the winner \\
\hline 4 & \multicolumn{2}{|c|}{1.095} & \multicolumn{2}{|c|}{1.053} & \multicolumn{2}{|c|}{1.044} & \multicolumn{2}{|c|}{1.049} & \\
\hline 5 & \multicolumn{2}{|c|}{1.034} & \multicolumn{2}{|c|}{1.038} & \multicolumn{2}{|c|}{1.039} & \multicolumn{2}{|c|}{1.030} & \\
\hline Average $(\mu)$ & \multicolumn{2}{|c|}{1.132} & \multicolumn{2}{|c|}{1.138} & \multicolumn{2}{|c|}{1.161} & \multicolumn{2}{|c|}{1.154} & Project Cost \\
\hline STD. Dev. $(\sigma)$ & \multicolumn{2}{|c|}{0.074} & \multicolumn{2}{|c|}{0.090} & \multicolumn{2}{|c|}{0.110} & \multicolumn{2}{|c|}{0.113} & $100,000,000$ \\
\hline Markup & Z & Pr. & Z & Pr. & Z & Pr. & Z & Pr. & Expected Profit \\
\hline $0 \%$ & -1.79 & 0.04 & -1.53 & 0.06 & -1.47 & 0.07 & -1.36 & 0.09 & - \\
\hline $1 \%$ & -1.65 & 0.05 & -1.42 & 0.08 & -1.38 & 0.08 & -1.27 & 0.10 & 720,459 \\
\hline $2 \%$ & -1.51 & 0.06 & -1.31 & 0.10 & -1.28 & 0.10 & -1.18 & 0.12 & $1,342,515$ \\
\hline $3 \%$ & -1.38 & 0.08 & -1.20 & 0.12 & -1.19 & 0.12 & -1.09 & 0.14 & $1,853,126$ \\
\hline $4 \%$ & -1.24 & 0.11 & -1.09 & 0.14 & -1.10 & 0.14 & -1.00 & 0.16 & $2,242,372$ \\
\hline $5 \%$ & -1.11 & 0.13 & -0.98 & 0.16 & -1.01 & 0.16 & -0.92 & 0.18 & $2,504,884$ \\
\hline $6 \%$ & -0.97 & 0.17 & -0.87 & 0.19 & -0.92 & 0.18 & -0.83 & 0.20 & $2,641,014$ \\
\hline $7 \%$ & -0.84 & 0.20 & -0.76 & 0.22 & -0.83 & 0.20 & -0.74 & 0.23 & $2,657,502$ \\
\hline $8 \%$ & -0.70 & 0.24 & -0.64 & 0.26 & -0.74 & 0.23 & -0.65 & 0.26 & $2,567,457$ \\
\hline $9 \%$ & -0.57 & 0.29 & -0.53 & 0.30 & -0.65 & 0.26 & -0.56 & 0.29 & $2,389,533$ \\
\hline $10 \%$ & -0.43 & 0.33 & -0.42 & 0.34 & -0.55 & 0.29 & -0.47 & 0.32 & $2,146,357$ \\
\hline
\end{tabular}

TABLE 9 | Bidder Selection using CSA.

\begin{tabular}{|c|c|c|c|c|c|c|}
\hline Bidder name & Current markup & Optimum markup & $\mathbf{k}$ & $K+1$ & TBC2 & TBC3 \\
\hline (1) & $(2)$ & (3) & (4) & (5) & (6) From Table 7 & $(7)=(5)(6)$ \\
\hline Ahmad & $10 \%$ & $7 \%$ & 0.03 & 1.03 & 4.006 & 4.126 \\
\hline Basim & $15 \%$ & $7 \%$ & 0.08 & 1.08 & 5.185 & 5.599 \\
\hline Cameron & $8 \%$ & $7 \%$ & 0.01 & 1.01 & 4.505 & 4.550 \\
\hline Danny & $12 \%$ & $6 \%$ & 0.06 & 1.06 & 3.702 & 3.924 \\
\hline Essam & $20 \%$ & $6 \%$ & 0.14 & 1.14 & 3.624 & 4.131 \\
\hline
\end{tabular}

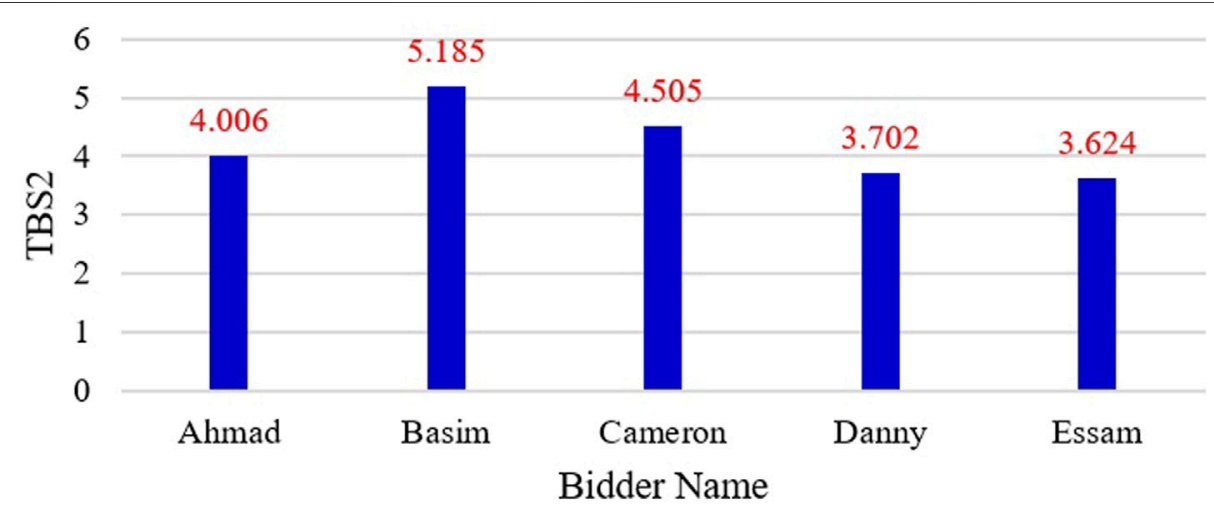

FIGURE 4 | Bidder ranking using the GSA

ratio-1. The lowest markup value is $8 \%$ by the bidder "Cameron". When the objective of the owner is to save the project cost without looking at the performance record of the bidder, the lowest value of the current markup is crucial for this selection. However, when the objective of the owner is to select a bidder, with respect to the bidder's previous performance record, the current markup is integrated with the bidder's performance record. The second indicator to determine the " $k$ " value is the winning markup. Using the historical data, which are collected by the owner, as shown in Table 3, the winning markup of each bidder can be estimated using Friedman's theory, in this research. Table $\mathbf{8}$ is an example of winning the current project by the first bidder "Ahmad" according to the $7 \%$ markup. Accordingly, the markup and " $k$ " value results of the five bidders are shown in Table 9. Finally, Equation 6 is carried out to determine 


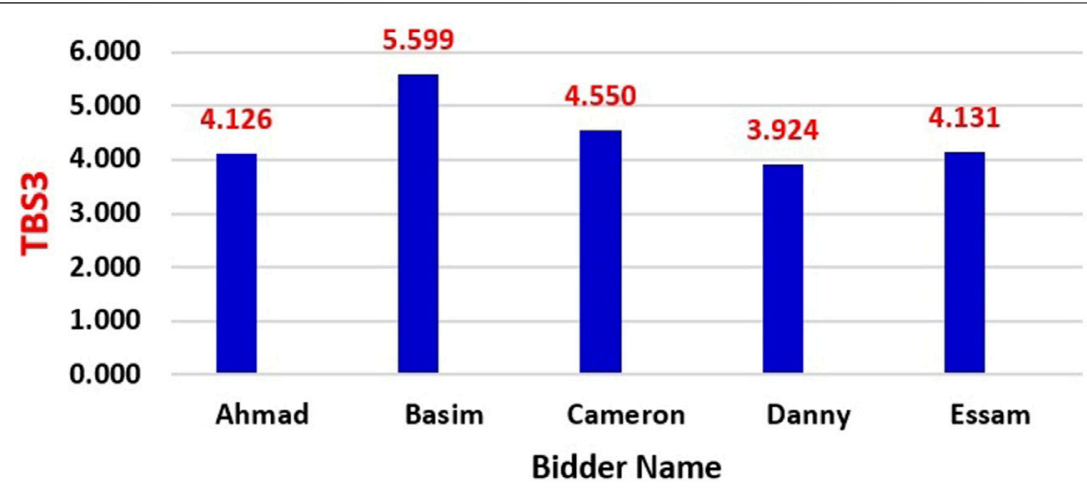

FIGURE 5 | Bidder ranking using the CSA

TBS3, as shown in Table 9 and Figure 5. The final selection using the CSA is depicted clearly in Figure 5. Danny has the lowest score; accordingly, he is the suitable bidder to perform the current 100-million dollar construction project. Ahmad is the second bidder on the shortlist, and he may be selected if Danny cannot fulfill the administrative requirements.

\section{DISCUSSION}

It should be noted that the results of the three approaches can be similar or different. The first approach (QSA) is easy and can be used for the small and low risk of construction projects, while the second approach (GSA) is necessary to be utilized to adjust the delay factors of the first approach when the associated risk is higher. This adjustment is obtained using one of the decision-making methods, such as the analytical hierarchy process (AHP). This method needs expert judgments to complete the process, which might affect the result of the bidder selection if the selected experts are not qualified to involve in such processes. The third approach (CSA), counters more risky factors than the first and the second approaches to get the suitable bidder. Adding more risky factors to compare between the competitors gives the owners a solid decision. However, risky factors may complicate the process of the selection, and therefore, adding these risk factors must be carried out according to the actual needs of the owners or developing a graphical user interface (GUI) to help the decision-makers. On the other hand, the third approach required enough data to be performed. More data give more reliable results. The missing parts of the required data do not affect the results when the Friedman theory is considered for the bidding process. Simply, the average and the standard deviation calculated are based on the available data. Missing data of the delay factors affect the process; therefore, either assume missing data or ignore factors without data.

\section{CONCLUSION}

The selection of a bidder to execute a multi-million construction project is a critical task. Fair selection is subjected to numerous factors. However, this task can be achieved using a specific and comprehensive system. A new bidder selection system is developed to deal with the performances of bidders with respect to previous experiences and biddings. The current system is based on the risk performance instead of the qualifications of the bidder. Hence, the minimum score is considered instead of the maximum, which is significantly utilized by project construction owners. Based on the available data and required level of the selection, three systematic systems are developed to help the selection by the owners. The quick selection approach (QSA) was based on the scoring of the historical delay factors, generic selection approach (GSA) for scoring and the importance weights of the delayed factors, and comprehensive selection approach (CSA) with respect to the bidding strategy and the scoring with the importance weights of the delayed factors. Construction management specialists have validated the three approaches. If the required data are available, the comprehensive selection (CSA) is found to be more efficient. As a result, owners of construction projects can rely on the developed models to choose the appropriate bidder based on the risk index's lowest value. The new work paves the way for future research in several areas, including the following:

i. A graphical user interface (GUI) is required to implement the three approaches.

ii. More research is required to include all types of construction contracts.

iii. More risk factors may be added to the developed models based on the nature of the new projects.

\section{Limitations}

The current research is limited to the following:

i. This is suitable for competitive bidding only. When all bidders are applied to win a project.

ii. All bidders are subject to the prequalification process according to different issues. A bidder is qualified to be on the shortlist when he/she fulfills all prequalification points.

iii. Ten delay factors are adopted in this research. However, the model is flexible to modify these factors with respect to ten only.

iv. A bidder is selected according to the minimum score value, which is a function of risk. 
v. The analytical hierarchy process (AHP) and Friedman theory are utilized to perform the developed models in this research. However, the model is flexible to adopt other methods to carry out the objectives of this research.

\section{DATA AVAILABILITY STATEMENT}

The original contributions presented in the study are included in the article/Supplementary Material; further inquiries can be directed to the corresponding author.

\section{ETHICS STATEMENT}

Ethical review and approval was not required for the study on human participants in accordance with the local legislation and institutional requirements. Written informed consent for

\section{REFERENCES}

Al-Adwani, M., Mollasalehi, S., and Fleming, A. (2018). "A Study of Root Causes of Delays in the Public - Sector Construction Projects in Kuwait," in International Conference on Construction Futures ICCF, March, UK: (University of Wolverhampton), 1-11. Available at: http://usir.salford. ac.uk/id/eprint/50346/.

Anthony, N., and Gates, R. S. (2007). Gates Bidding Model QUT Digital Repository. Am. Soc. Civil Eng. (ASCE), 9364. doi:10.1061/(ASCE)07339364(2007)133

Araujo, M. C. B., Alencar, L. H., and Mota, C. M. M. (2015). "Contractor Selection in Construction Industry: A Multicriteria Model," in IEEE International Conference on Industrial Engineering and Engineering Management (Singapore), 519-523. doi:10.1109/IEEM.2015.7385701

Ballesteros-Pérez, P., González-Cruz, M. C., Fernández-Diego, M., and Pellicer, E. (2014). Estimating Future Bidding Performance of Competitor Bidders in Capped Tenders. J. Civil Eng. Manage. 20 (5), 702-713. doi:10.3846/ 13923730.2014.914096

Bekr, G. (2017). “Addressing Crucial Risk Factors in the Middle East Construction Addressing Crucial Risk Factors in the Middle East Construction Industries : a Comparative Study of Saudi," in Sustainable Building Conference 2013, Coventry, UK, July 2013 (Coventry University).

Carr, R. I. (1982). General Bidding Model. J. Construct. Div. Am. Soc. Civil Eng. 108 (3), 639-649.

Cheng, M.-Y., Hsiang, C.-C., Tsai, H.-C., and Do, H.-L. (2011). Bidding Decision Making for Construction Company Using a Multi-Criteria Prospect Model/ Statybos Imonès Apsisprendimas Dalyvauti Konkurse Naudojant Daugiakriterinị Perspektyvų Modelị. J. Civil Eng. Manage. 17 (3), 424-436. doi:10.3846/13923730.2011.598337

Christodoulou, S. (2010). Bid Mark-up Selection Using Artificial Neural Networks and an Entropy Metric. Eng. Const Arch. Man. 17 (4), 424-439. doi:10.1108/ 09699981011056600

De Araujo, M. C. B., Alencar, L. H., and Mota, C. M. M. (2017). "Model for Contractor Performance Evaluation in Construction Industry," in 2016 IEEE International Conference on Systems, Man, and Cybernetics, SMC 2016 Conference Proceedings, March 2020 (Budapest, Hungary), 2631-2635. doi:10.1109/SMC.2016.7844636

Fashina, A. A., Omar, M. A., Sheikh, A. A., and Fakunle, F. F. (2021). Exploring the Significant Factors that Influence Delays in Construction Projects in Hargeisa. Heliyon 7 (4), e06826. doi:10.1016/j.heliyon.2021.e06826 participation was not required for this study in accordance with the national legislation and the institutional requirements.

\section{AUTHOR CONTRIBUTIONS}

The author confirms being the sole contributor of this work and has approved it for publication.

\section{ACKNOWLEDGMENTS}

We would like to express our gratitude to Dr.Murad Althobaiti [The dean of the college of engineering (CEO)- Imam Abdulrahman Bin Faisal University (IAU)] and all the college faculties, employees, and students, for providing us with the opportunity to complete this fantastic project.

Friedman, L. (1956). A Competitive-Bidding Strategy. Operations Res. 4, 104-112. doi:10.1287/opre.4.1.104

Gomarn, P., and Pongpeng, J. (2018). Causes of Construction Delay from Contractors and Suppliers in Thailand's Oil and Gas Platform Projects. MATEC Web Conf. 192, 02008-02011. doi:10.1051/matecconf/ 201819202008

Hussain, M., Ajmal, M. M., Khan, M., and Saber, H. (2015). Competitive Priorities and Knowledge Management. J. Manufacturing Tech. Manage. 26 (6), 791-806. doi:10.1108/JMTM-03-2014-0020

Jaskowski, P., Biruk, S., and Czarnigowska, A. (2019). Strategy for Mark-Up Definition in Competitive Tenders for Construction Work. IOP Conf. Ser. Mater. Sci. Eng. 471 (11), 112060-112069. doi:10.1088/1757-899X/471/11/ 112060

Kembłowski, M. W., Grzyl, B., and Siemaszko, A. (2017). Game Theory Analysis of Bidding for A Construction Contract. IOP Conf. Ser. Mater. Sci. Eng. 245 (6), 062047-62111. doi:10.1088/1757-899X/245/6/062047

Liang, R., Sheng, Z., Xu, F., and Wu, C. (2016). Bidding Strategy to Support Decision-Making Based on Comprehensive Information in Construction Projects. Discrete Dyn. Nat. Soc. 2016, 1-15. doi:10.1155/ 2016/4643630

Marzouk, M., and Moselhi, O. (2003). A Decision Support Tool for Construction Bidding. Construction Innovation 3 (2), 111-124. doi:10.1108/ 14714170310814882

Modor Intelligence (2019). Saudi Arabia Construction Market Size, Report Analysis, Forecast 2019-24.

Profile, S. E. E. (2016). A Review on Strategy of Bidding and Competitive Bidding Process. Ijaerd 3 (04). doi:10.21090/ijaerd.030435

Rao, C. J. (2013). Auction Methods of Homogeneous Goods Such as Mine and Energy Material. Amm 246-247, 556-560. doi:10.4028/www.scientific.net/ AMM.246-247.556

Ruqaishi and Bashir (2015). Industry in the Gulf Cooperation Council Countries: A Case Study. J. Manag. Eng. 31 (3), 05014017. doi:10.1061/(asce)me.19435479.0000248

Rzepecki, Ł., and Jaśkowski, P. (2021). Application of Game Theory against Nature in Supporting Bid Pricing in Construction. Symmetry 13 (1), 132-214. doi:10.3390/sym 13010132

Van, L. T., Sang, N. M., and Viet, N. T. (2016). A Conceptual Model of Delay Factors Affecting Government Construction Projects. ARPN J. Sci. Tech. 5 (2), 92-100.

Yang, X. (2018). Research on Bidding Strategy of Construction Project. Ifmeita 2017 130, 277-281. doi:10.2991/ifmeita-17.2018.48 
Yap, J. B. H., Goay, P. L., Woon, Y. B., and Skitmore, M. (2021). Revisiting Critical Delay Factors for Construction: Analysing Projects in Malaysia. Alexandria Eng. J. 60 (1), 1717-1729. doi:10.1016/j.aej.2020.11.021

Yuliana, C., Kartadipura, R. H., and Taufik, S. (2016). Bidding Strategy Using Friedman Model for Building Construction Project in Banjarbaru Indonesia. J. Civil, Construction Environ. Eng. 1 (1), 12-17. doi:10.11648/j.jccee.20160101.12

Zidane, Y. J. T., and Andersen, B. (2018). Causes of Delay and Their Cures in Major Norwegian Projects. J. Mod. Project Manage. 5 (3), 80-91. doi:10.19255/ JMPM01509

Conflict of Interest: The author declares that the research was conducted in the absence of any commercial or financial relationships that could be construed as a potential conflict of interest.
Publisher's Note: All claims expressed in this article are solely those of the authors and do not necessarily represent those of their affiliated organizations, or those of the publisher, the editors, and the reviewers. Any product that may be evaluated in this article, or claim that may be made by its manufacturer, is not guaranteed or endorsed by the publisher.

Copyright (c) 2022 Salman. This is an open-access article distributed under the terms of the Creative Commons Attribution License (CC BY). The use, distribution or reproduction in other forums is permitted, provided the original author(s) and the copyright owner(s) are credited and that the original publication in this journal is cited, in accordance with accepted academic practice. No use, distribution or reproduction is permitted which does not comply with these terms. 